\title{
Immersive virtual environment technology as a basic research tool in psychology
}

\author{
JACK M. LOOMIS and JAMES J. BLASCOVICH \\ University of Califormia, Santa Barbara, California \\ and \\ ANDREW C. BEALL \\ Massachusetts Institute of Technology, Cambridge, Massachusetts
}

\begin{abstract}
Immersive virtual environment (IVE) technology has great promise as a tool for basic experimental research in psychology. IVE technology gives participants the experience of being surrounded by the computer-synthesized environment. We begin with a discussion of the various devices needed to implement immersive virtual environments, including object manipulation and social interaction. We review the benefits and drawbacks associated with virtual environment technology, in comparison with more conventional ways of doing basic experimental research. We then consider a variety of examples of research using IVE technology in the areas of perception, spatial cognition, and social interaction.
\end{abstract}

Human history records a progression of artifacts for representing and recreating aspects of external reality, ranging from language, drawings, and sculpture in earlier times to the more modern artifacts of photographs, movies, television, and audio recordings. Relatively recently, the digital computer and its associated technologies, including three-dimensional (3-D) graphics, have given rise to increasingly realistic artifacts that blur the distinction between reality and its representation (Ellis, 1995).

The ultimate representational system would allow the observer to interact "naturally" with objects and other individuals within a simulated environment or "world," an experience indistinguishable from "normal reality." Although such a representational system might conceivably use direct brain stimulation in the future, it will more likely use digitally controlled displays that stimulate the human sensory organs, the natural conduits to the brain.

Displays of this type, referred to as virtual displays (VDs), although far from ideal, exist today. Following the terminology of others (e.g., Durlach \& Mavor, 1995; Stanney \& Salvendy, 1998), we refer to the corresponding environment represented and stored in the computer and experienced by the user as a virtual environment (VE). Virtual environment technology (VET) refers inclusively both to VDs and to the VEs so created, including VEs produced by using conventional desktop computer displays.

With the support of Grant N00014-95-1-0573 from the Office of Naval Research (to J.M.L.) and National Science Foundation Grants SBR 9872084 (to J.J.B.) and SBR 9873432 (to J.M.L. and J.J.B.), and with additional support from the University of California, Santa Barbara, the authors have developed several immersive virtual displays, use of which has stimulated many of the ideas expressed here. The authors thank Florence Gaunet and Patrick Péruch for comments on an earlier version of the article. Correspondence concerning this article should be addressed to J. M. Loomis, Department of Psychology, University of California, Santa Barbara, CA 93106 (e-mail: loomis@psych.ucsb.edu).
(Virtual reality is widely used as an alternative term, but we prefer VE.) An immersive virtual environment (IVE) is one in which the user is perceptually surrounded by the VE. Ivan Sutherland (1965), one of the originators of 3-D computer graphics, was the first person to conceive and build an immersive VD system. For the history of IVEs, see Ellis (1995), Kalawsky (1993), and Rheingold (1991).

There are two usual implementations of an IVE. The first of these involves placing multiple projection screens and loudspeakers around the user. A popular design is the CAVE (Cruz-Neira, Sandin, \& DeFantini, 1993), which involves back-projecting the computer-generated visual imagery onto the translucent walls, floor, and ceiling of a moderately sized cubical room, in which the user is free to move; shutter glasses provide stereoscopic stimulation, so that one sees the VE not as projections on the room surfaces, but as solid 3-D structures within and/or outside of the cube. The second and more common implementation of an IVE involves the use of a head-mounted display (HMD), used in conjunction with a computer and a head tracker (Barfield \& Furness, 1995; Biocca \& Delaney, 1995; Burdea \& Coiffett, 1994; Durlach \& Mavor, 1995; Kalawsky, 1993). The head tracker measures the changing position and orientation of the user's head within the physical environment, information that is communicated to the rendering computer, which has stored within it a 3-D representation of the simulated environment (Meyer, Applewhite, \& Biocca, 1992). At any given moment, the computer generates and outputs the visual and auditory imagery to the user's HMD from a perspective that is based on the position and orientation of the user's head. The HMD consists of earphones and video displays attached to a support worn on the head; the video display component is based on cathode ray tube (CRT) displays, liquid crystal displays, or laser-based retinal scanners (Barfield, Hendrix, Bjorneseth, Kaczmarek, \& 
Lotens, 1995; Holmgren \& Robinett, 1993). In many implementations using HMDs, binocular (stereoscopic) visual imagery provides convergence and retinal disparity cues that contribute to the perception of egocentric distance and exocentric depth. Virtual or "spatialized" sound is created by using special-purpose hardware and software that generates binaural signals typically presented by earphones; the result is that the user hears sounds appearing to emanate from surrounding auditory space (Begault, 1994; Carlile, 1996; Gilkey \& Anderson, 1997; Loomis, Klatzky, \& Golledge, 1999; Wenzel, 1992). With a properly designed system using either HMDs or projection screens and loudspeakers, the user receives binocular and binaural stimulation approximating the stimulation he or she would receive if moving about within a real physical environment equivalent to that stored within the computer. Under these circumstances, individuals experience a compelling sense of immersion or presence within the VE (Barfield, Zeltzer, Sheridan, \& Slater, 1995; Heeter, 1992; Held \& Durlach, 1992; Loomis, 1992; Sheridan, 1992; Slater, Usoh, \& Steed, 1994; Stanney \& Salvendy, 1998; Steuer, 1995).

The discussion so far has focused on visual and auditory stimulation. For haptic stimulation, force feedback devices and inflatable gloves provide modest degrees of kinesthetic and cutaneous stimulation of the hands and fingers (Barfield \& Furness, 1995; Biocca \& Delaney, 1995; Burdea \& Coiffett, 1994; Durlach \& Mavor, 1995; Iwata, 1999; Kalawsky, 1993). Eventually, advanced haptic interfaces might allow a person to use the hands and fingers to feel and identify objects, sense the layout of surfaces, and so forth.

For naturalistic interaction with virtual objects, the user needs a means of manual control and even of manipulation. Sensors attached to the hands and fingers allow tracking of users' positions and orientations (Biocca \& Delaney, 1995). This information, from which manual gestures can be decoded, can be used in a multitude of ways, to allow the person to manipulate and otherwise interact with virtual objects.

For social IVEs, two basic approaches afford social interaction. The first requires the computer to model intelligent interactants other than the user. Although fairly realistic simulations of dogs, cats, and other pets are feasible, realistic modeling of people as interactants remains a major challenge in artificial intelligence. The second approach requires immersion of additional real individuals within the same VE. Although conceptually straightforward, implementation will require surmounting many hardware and software challenges. For realistic social interaction beyond speech, one needs specialized sensors for tracking eye gaze, facial expressions, hand gestures, and body language for both (or all) interactants (Biocca \& Delaney, 1995). The graphics computer then renders the nonverbal behavior of each interactant by way of modifications of a stored graphics model of that individual.
In the typical IVE implementation using an HMD, the user is visually isolated from the real environment. Augmented reality (or mixed reality) avoids this isolation by permitting the user to see both the real environment and the VE (see, e.g., Ohta \& Tamura, 1999). When an HMD is used, augmented reality is most effectively accomplished with see-through video techniques (Fuchs \& Ackerman, 1999; Tamura, Yamamoto, \& Katayama, 1999). Here, the user sees the real environment by way of video cameras attached to the helmet; image processing techniques are used to produce natural occlusion of the virtual entities by real entities (from the cameras), or vice versa. Although effecting natural occlusion remains a major challenge, achieving positional stability of the virtual entities with respect to the real environment is even more difficult, because spatial inaccuracy, noise, and temporal lag of the head tracking all result in imperfect registration and relative movement of the virtual imagery with respect to the objects in the real environment.

\section{ADVANTAGES OF IMMERSIVE VIRTUAL ENVIRONMENT TECHNOLOGY AS A RESEARCH TOOL}

In psychology, experimental researchers have traditionally confronted the choice between experimental control and ecological validity (see Figure 1), with experimental control being regarded as the sine qua non of the field. Consequently, most experimentalists create controlled and contrived situations in sterile artificial environments, or laboratories, and employ specialized devices

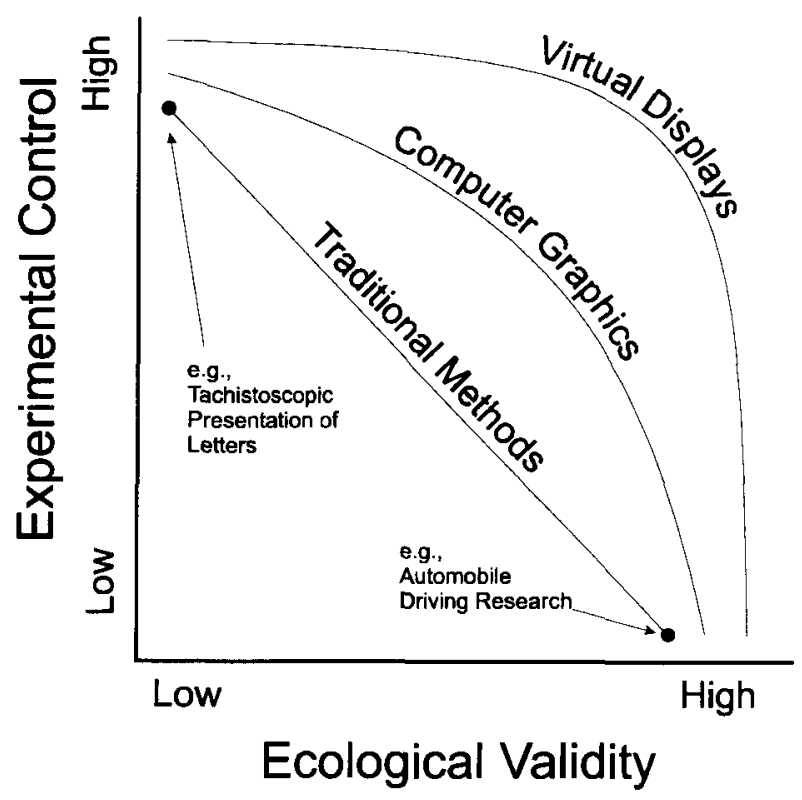

Figure 1. Experimentation in psychology entails a tradeoff between experimental control and ecological validity. Virtual displays, especially immersive ones, afford less of a tradeoff than do traditional approaches to psychological experimentation. 
allowing precise control over the delivery of stimuli. In the early days of visual perception research, for example, the tachistoscope represented one extreme; this was a device for presenting a small number of two-dimensional pictures for very brief durations. It permitted good stimulus control, but at a huge cost in ecological validity. Moving about in natural settings, such as automobile driving, represented the other extreme-high ecological validity, but very limited experimental control.

Advances in audio and video recording equipment have allowed researchers to expand the operating characteristic depicted in Figure 1 outward, thereby decreasing the degree of tradeoff between control and validity. Three-dimensional computer graphics and digital sound synthesis have continued this trend, with high-end flight simulation being the most successful application of these technologies in recent years (Moroney \& Moroney, 1999). However, immersive VDs, by virtue of their being nearly optimal interfaces for the human senses, have the potential for maximally expanding the operating characteristic, thereby providing high ecological validity without compromising experimental control, and vice versa. Such a change in the operating characteristic afforded by IVE technology will very likely promote rapid advancement and application of psychological science by increasing the generalizability of experimental findings and the theories based on them.

In addition, VET will increase the power of experimental research, because of the increases in experimental realism - the impact of manipulations on participants. In much of cognitive and social psychology, for example, manipulations often involve the induction of cognitive or affective states by written passages, verbal instructions, videotapes, and sounds. The effectiveness of these inductions, in terms of their variability across participants, is limited by the attentional, motivational, and imaginative capacities of the research participants. By more directly eliciting the participants' cognitive and affective processes, IVE technology substantially augments these capacities by increasing the effectiveness of many experimental inductions, thereby increasing experimental realism and reducing the variability in the results of these manipulations and inductions. For example, one can more easily elicit fear associated with acrophobia in VEs, as compared with imagery and other techniques, even with the participant being fully aware of the unrealistic nature of such fear within a VE (Rothbaum et al., 1995).

Importantly, IVE technology gives researchers the ability to perform manipulations impossible, or nearly so, with any other means. For example, in the physical world, many stimulus variables (e.g., the egocentric distance of an object and its angular size) are highly correlated. IVE technology affords the decoupling of such variables. In some of our research employing a VE, for example, we have held the angular size of an object constant as the subject moves relative to it, thus eliminating its visual angle as a distance cue (Gaunet \& Loomis, 1999), a decoupling most difficult to achieve with ordinary means. Changing the shape of an object contingent on the subject's relative location or even the subject's behavior provides another example. Thus, in a driving study, one can selectively alter aspects of the road ahead to determine how much of the forward field of view influences the driver's steering. In the social realm, with IVE technology, one can manipulate even organismic variables, such as a participant's apparent gender, race, weight, and so forth, enabling heretofore practically impossible examinations of social identity, roles, and stereotypes. Also, the researcher can decouple nonverbal behavior that an interactant displays from what another interactant perceives; for example, the eye gaze or facial expressions of interactant $A$ can be systematically altered in the graphic rendering, so that interactant $B$ sees something quite different, thus affording novel basic research on nonverbal communication and contributing to the development of realistic applications involving social interaction in IVEs.

Another advantage provided by IVE technology stems from the ease with which investigators can implement and conduct experiments. In the area of visual perception, for example, IVE technology facilitates the creation of naturalappearing VEs for studying space perception, color perception, and so forth. Although investigators can create specially designed natural environments in the laboratory (e.g., Brainard, Brunt, \& Speigle, 1997), such creations entail the investment of much time and expense. In contrast, once one has acquired a VD system, creation of new IVEs requires only programming effort. In addition, cumbersome rearrangements of a physical laboratory that can take hours, if not days, can happen practically instantaneously with IVE technology

IVE technology also provides a largely new and practical data source. For example, in the area of perception and action, one often needs to make measurements of the participant's walking and hand trajectories, as in experiments on visually controlled locomotion or visually guided reaching, respectively. Because IVE implementation requires these measurements, they are automatically available for data analysis in IVE-based experiments. For example, in the area of nonverbal communication, IVE technololgy will actually facilitiate research on mutual eye gaze between multiple interactants, because the eye tracking measurements required to effect natural eye gaze in IVEs will also provide the necessary data for analysis of eye gaze patterns; heretofore, analysis of mutual eye gaze, especially in group settings, has been greatly limited by the unavailability of such measurements.

\section{DISADVANTAGES OF IMMERSIVE VIRTUAL ENVIRONMENT TECHNOLOGY AS A RESEARCH TOOL}

Whenever one attempts to abstract the real world within the laboratory, some loss in ecological validity always occurs. As was argued above, IVE technology offers the possibility of increasing ecological validity above that common in laboratory research today. At the same time, 
however, the imperfection and high complexity of IVE hardware and software greatly increase the likelihood of artifacts' contaminating the research findings, especially in areas such as perception, where the sensory stimulation requires high accuracy. Imperfections in the rendering models (e.g., for illumination), limitations of the visual display (e.g., low spatial resolution, small field of view, and fixed accommodative distance), slow graphics update rate, and significant lags between head tracking and visual display are all sources of artifact for this type of research (Barfield, Hendrix, et al., 1995; Peli, 1995). For research concerned with more abstract processes relating to cognition and social interaction, it is likely that the risk of artifacts will derive less from imperfections in the visual display and more from the computer models used in rendering the environment and other interactants. Imperfections in the technology, whether associated with tracking and display hardware or with modeling software, will continue to impede certain types of research until the technology improves. In view of these concerns, researchers using IVE technology need to be vigilant about possible limitations to the validity of their research.

Although IVE technology offers increased ecological validity through more complex, but controlled, stimulation, specification of the stimulation becomes formidable. For laboratories using the same IVE implementation, the sharing of software, which allows for exact replication, can circumvent the problem. However, given that few laboratories will actually use the same implementation, the problem may persist, although we note that few, if any, physical laboratories are the same across researchers.

The difficulty of setting up a high-quality IVE laboratory is another disadvantage of IVE technology, at least in the near term. We can anticipate turnkey systems in the more distant future. Until then, the complexity of current IVE implementations will demand individuals with considerable skill in programming and interfacing. Consequently, adoption of IVE technology will be slow to meet the burgeoning interest.

A final and very significant disadvantage of using IVE technology is the common occurrence of aftereffects experienced by many participants (see the excellent overview by Stanney \& Salvendy, 1998). Aftereffects include symptoms of motion (simulator) sickness, disturbance of balance and of eye-hand coordination, drowsiness, and even instances of memory "flashbacks." Research indicates that the incidence of these aftereffects depends greatly on characteristics of the participants and specific features of the IVE implementation (e.g., display field of view, tracker lag; Stanney \& Salvendy, 1998). Although IVE technology continues to improve, the complex etiology of these aftereffects means that these aftereffects will continue to plague IVE research well into the future and that researchers will have to develop ways of mitigating these effects, including improved selection of participants and excusing participants from the experiment at the onset of the earliest discernible symptoms.

\section{EXAMPLES OF RESEARCH USING IMMERSIVE VIRTUAL ENVIRONMENT TECHNOLOGY}

This section presents examples of basic research, some already reported in print or at conferences. The purpose is to convey the unique capabilities of IVE technology for furthering psychological science.

\section{Visual Perception and Action}

The area of visual space perception has benefited and will continue to benefit from the use of IVE technology. One important reason is that, in comparison with more conventional 3-D computer graphics displayed on desktop CRTs, an immersive VD, even one employing an HMD, can give the user the perceptual experience of being inside a large-scale environment (e.g., a large room, a building, an outdoor setting). This means that the researcher can investigate the perception of distance, size, and motion at larger scales not permitted by conventional CRTs and yet have the convenience of computerbased research (e.g., Beall, Loomis, Philbeck, \& Fikes, 1995; Ellis \& Menges, 1997, 1999; Loomis \& Knapp, in press; Proffitt, Bhalla, Gossweiler, \& Midgett, 1995; Rolland, Gibson, \& Arierly, 1995; Surdick, Davis, King, \& Hodges, 1997; Witmer \& Kline, 1998; Witmer \& Sadowski, 1998; Yang, Dixon, \& Proffitt, 1999). Why HMDbased IVE technology permits the experience of large objects and environments is itself an interesting question. Possibly, the HMD implementation avoids the perceptual conflict accompanying traditional screen-based vision research - that between the intended size of the simulated 3-D object and its image size as rendered on the display (for a discussion of a related issue, see Pirenne, 1970). An elegant way of testing this hypothesis is to simulate projection surfaces, such as CRTs or movie screens, within the virtual environment (Yang et al., 1999); in this way, one can vary the size of the simulated 3-D object independently of its projected image on the simulated projection surface.

We note, however, a significant limitation of HMDbased IVEs for investigating visual space perception at near distances. Because the accommodative distance of the displays is fixed (usually close to optical infinity), there is a necessary conflict between accommodation and other distance cues, such as convergence (Ellis \& Menges, 1997; Peli, 1995). Besides resulting in incorrect distance information for near objects, the conflict can also interfere with proper binocular fusion, especially among younger participants, for whom accommodation is most effective.

Acrophobia is another topic that involves visual space perception but goes well beyond it. The fascinating work of Rothbaum et al. (1995) has shown that acrophobes, although well aware that they are in an IVE, readily experience palpable fear when positioned at simulated high locations. Moreover, this research has demonstrated the efficacy of IVE phobia desensitization (see also Roth- 
baum, Hodges, \& Kooper, 1997). For our present concern, however, we point out the value of using IVE technology to better understand the process of acrophobia elicitation. Besides the obvious manipulations of distance cues to determine the ones most important in creating the impression of being up high, other cues concern sensorimotor integration. For example, does pure visual information elicit acrophobia, or must appropriate head orientation, signaled by neck proprioception and vestibular cues (e.g., looking down from a high bridge) accompany the visual information? To answer this, one can decouple the participant's visual stimulation from his or her head orientation, so that exactly the same visual information is presented with the head facing downward (normal coupling) or facing upward (decoupled).

For the topic of visually controlled action, IVE technology has enormous potential, because the coupling between the participant's motor activity and the resulting visual stimulation can be readily modified. In connection with the visual control of walking, for example, the researcher can modify the coupling between the optic flow field and the participant's motor commands to the legs and feet (see, e.g., Warren \& Kay, 1997), so that the proprioceptive inputs signaling travel direction are discrepant with respect to the optic flow. Similarly, in evaluating the influence of moving objects on the ability of a participant to aim his or her walking toward a target object, one can laterally displace objects or a substantial portion of the simulated environment (like walking in surf) and measure the influence of the subsequent optic flow on the measured trajectory of the participant. The visual control of ball catching and batting are also natural topics for IVE technology, because the experimenter can easily manipulate various aspects of the ball's trajectory, as well as the participant's visual feedback about his or her $\mathrm{arm} / \mathrm{hand}$, in order to determine the information critical to performance (see McBeath, Shaffer, \& Kaiser, 1995). An exciting new development that will be a boon to research on perception/action is the recent integration of eye trackers into HMDs. This will permit the monitoring of eye fixation patterns while participants carry out complex spatial behaviors, all within the safety of the VE laboratory.

\section{Spatial Cognition}

Spatial cognition research has already embraced VET (Chance, Gaunet, Beall, \& Loomis, 1998; Darken \& Sibert, 1996; Gillner \& Mallot, 1998; Klatzky, Loomis, Beall, Chance, \& Golledge, 1998; May, Péruch, \& Savoyant, 1995; Péruch \& Gaunet, 1998; Péruch, May, \& Wartenberg, 1997; Péruch, Vercher, \& Gauthier, 1995; Regian, Shebilske, \& Monk, 1992; Richardson, Montello, \& Hegarty, 1999; Rossano \& Moak, 1998; Wilson, Foreman, Gillett, \& Stanton, 1997; Witmer, Bailey, \& Knerr, 1996). Much of the appeal of VET is the ease with which one can create complex environments for participants to explore. Péruch and Gaunet (1998) discuss in detail the advantages and disadvantages of VET for study- ing spatial cognition and review much of the research that has been done.

As is now widely recognized, spatial navigation relies on two distinct processes: piloting and path integration. Piloting relies on position fixing on the basis of environmental cues, such as landmarks, whereas path integration involves updating one's estimate of current position on the basis of the integration of self-motion (Gallistel, 1990; Golledge, 1999). One strategy for understanding human navigation ability is to first investigate the functional properties of the two processes in isolation and then to study them together. IVE technology provides the means for investigating the two in isolation. For example, to study path integration based on visual input, one can use an IVE to provide good optic flow information for the sensing of self-motion while eliminating any environmental position cues (e.g., Chance et al., 1998; Klatzky et al., 1998). Conversely, one can use an IVE to investigate piloting apart from any involvement of path integration. Gaunet and Loomis (1999) studied the ability of participants to find their way back to a target location specified by several visible landmarks; by rotating and translating the virtual environment with respect to the physical laboratory on each trial, any estimate of current location based on path integration by physical walking was rendered useless. Related research investigating selflocalization using landmarks has been done with desktop VEs (Jacobs, Laurance, \& Thomas, 1997; Sandstrom, Kaufman, \& Huettel, 1998). An important advantage of IVEs over real environments is that the experimenter can be assured that self-localization is not mediated by any incidental positional cues, for only those cues included in the 3-D spatial database are perceptible to the participant.

Cognitive mapping, the acquisition of environmental knowledge, is another topic ideally suited for IVE technology (see, e.g., Rossano \& Moak, 1998; Wilson et al., 1997: Witmer et al., 1996). Besides making this research much easier, IVE technology also allows manipulations that would be impossible in the real world. Not only can one readily manipulate local environmental cues, one can also manipulate large distal features (e.g., mountains), as well the overall shape of the environment, in order to assess which aspects are most important for cognitive mapping. For researchers wishing to have participants walk or be conveyed by a real vehicle through very large scale IVEs, the coupling of Global Positioning System receivers with portable computers is beginning to make this possible (vision: Feiner, MacIntyre, \& Höllerer, 1999; audition: Loomis, Golledge, \& Klatzky, 1998).

Still another spatial cognition topic that will benefit from IVE technology is memory for the locations of hidden objects (see, e.g., Hermer \& Spelke, 1996; Huttenlocher, Newcombe, \& Sandberg, 1994). IVE technology will greatly facilitate research dealing with 3-D spatial memory, since an unlimited number of objects can be hidden, with each object being rendered visible when the participant arrives within its vicinity or investigates its hiding location. Moreover, manipulations, such as exchanging 
hidden objects or modifying their appearance, can be accomplished with just a little programming effort.

\section{Social Interaction}

Although IVE technology has already proven valuable for perception and spatial cognition researchers, its methodological potential extends to other areas of psychology and behavioral science, even to such a complex domain as social behavior. Experimental social psychologists and others study social interaction in many ways but usually employ one of two types of techniques for developing interaction scenarios. Most frequently, they investigate social interaction by employing a bona fide participant and a simulated (nondigital) other. Social interaction researchers commonly simulate the presence of other interactants via verbal or written information (i.e., vignettes), via voice or video recordings of supposed others (i.e., actors), and via live human actors or confederates. One might assume that the more realistic the technique (i.e., live actors), the greater the experimental impact of the simulated other. However, as the difficulty of precisely controlling simulated others increases with the use of increasingly realistic but nondigital techniques, experimental control is lessened (again, see Figure 1). Given this state of affairs, not surprisingly, most complex manipulations of simulated other characteristics employ the least realistic and impactful techniques (i.e., vignettes, as opposed to live actors). The more realistic techniques even preclude some types of precisely controlled manipulations. For example, using actors, one cannot manipulate organismic variables, such as the sex or the race of the other, keeping every other physical characteristic the same. Finally, of course, the more "others" that one needs to include in an experiment (e.g., small group research), the less practical are realistic techniques, such as those employing actual confederates.

IVE technology provides a potential solution to the problems of simulating others, using traditional techniques. As we have argued, IVEs substantially increase the experimental realism of manipulations. They provide far more impactful manipulations than those attempted via vignettes, audio recordings, and videotape. Hence, by using IVE technology to immerse participants in impactful virtual worlds, one can precisely control the actions and appearances of others. For example, using VET, one can run interpersonal attraction studies, employing a wide variety of lifelike simulated others varying on characteristics hypothesized to influence attraction. Or, in studies on stereotypes, one could vary virtual others only on those characteristics important theoretically, such as sex, race, physical size, and so forth, while keeping constant all other physical features. Thus, for example, if one wanted to systematically study the effects of the weight of a target individual on the social perceptions of that target by others, IVE technology would allow a realistic simulation in which only the weight dimension was varied. Finally, one can create and control virtual groups of others to study small group dynamics.
Social psychologists and others also study interaction among two or more bona fide participants but do so less frequently. These types of investigations obviously preclude much control over the behaviors of the interactants and, thus, experimental manipulations of the interactants' actions. Although such necessarily observational approaches to real social interaction provide important and valuable information, they provide less inferential power regarding theory and hypothesis testing. IVE technology represents a valuable tool in these types of studies as well, because IVEs allow two or more individuals to interact within the same virtual world (Benford et al., 1995; Palmer, 1995; Stone, 1993). At the same time, IVE technology allows selective and systematic filtering or alteration of the appearance of the other's actions to each participant. Thus, one can select certain behavioral features that are theorized to influence interaction and then control or manipulate only those features. For example, in studies of nonverbal behaviors believed to be crucial to the fabric of social interaction, such as mutual gaze or interpersonal distance, one can systematically alter only the gaze or the interpersonal distance aspects of the virtual representations of participants, thereby allowing strong tests of theorized functions of this important nonverbal aspect of social interaction. An experimenter could vary the simulated eye gaze of a male interactant from gaze aversion to staring or leering, without his knowledge, and determine the influence of this manipulation on the interaction between the male and a female interactant, both of whom inhabit the same virtual environment. Even without such filtering and manipulation, IVE technology contributes to the ease with which studies of uncontrolled social interactions can be done by providing a complete digitized record of all interactant actions and movements.

\section{SOURCES OF INFORMATION ABOUT IMMERSIVE VIRTUAL ENVIRONMENT TECHNOLOGY}

Two edited books are good sources about IVE technology as it relates to various research issues in psychology. Besides covering software and hardware technology, both the volume by Barfield and Furness (1995) and that by Durlach and Mavor (1995) review in detail the properties of vision, audition, somesthesis, and kinesthesia as they relate to advanced interface design. The book by Biocca and Levy (1995) is a good introduction to IVE technology; in addition, many of its chapters treat an issue rarely addressed by other IVE researchers-social communication. Two other excellent sources of information about IVE technology and its applications are the volumes authored by Burdea and Coiffett (1994) and by Kalawsky (1993). Finally, three recent volumes deal with auditory perception and virtual acoustic displays (Begault, 1994; Carlile, 1996; Gilkey \& Anderson, 1997), and a forthcoming book is concerned with perception, cognition, human performance, and applications of VET (Hettinger \& Haas, in press). 
Presence: Teleoperators and Virtual Environments, the journal most relevant to basic psychological research in IVEs, is devoted to a wide spectrum of research and development of IVE technology. CyberPsychology \& Behavior focuses on VEs and multimedia and is more applied, with articles devoted to psychiatry, the sociological impacts of VEs, and so forth. Human Factors, International Journal of Human-Computer Interaction, and ACM Transactions on Computer-Human Interaction are three other journals that regularly have articles devoted to applied research involving VET and psychology.

Three regularly held conferences in the United States, with published proceedings that include papers on IVE technology relating to basic psychological research, are the IEEE Virtual Reality Symposium (formerly VRAIS), the International Conference on Auditory Display (ICAD), and the Annual Symposium on Haptic Interfaces for Virtual Environments and Teleoperator Systems. Presence: Teleoperators and Virtual Environments has a listing in each issue of upcoming conferences relating to VEs.

Finally, the Internet provides a good source of information on IVE, with many sites describing commercially available hardware and software, entertainment uses, engineering and medical applications, and applied and basic human research.

\section{SUMMARY}

IVE technology is a highly promising tool for the study of basic psychological processes. Its primary advantages are affording more ecological validity without compromising experimental control and allowing the decoupling of variables that naturally covary. We have provided examples of research from the areas of perception, spatial cognition, and social interaction, but surely many other areas of psychology will benefit as well from this technology.

\section{REFERENCES}

BARFIEld, W.. \& Furness. T. A.. III (1995). Virtual environments and advanced interface design. New York: Oxford University Press.

Barfield, W., Hendrix. C.. Buorneseth, O., Kaczmarek. K. A., \& LOTENS. W. (1995). Comparison of human sensory capabilities with technical specifications of virtual environment equipment. Presence: Teleoperators \& Virtual Environments, 4, 329-356.

Barfield, W. . Zeltzer, D., Sheridan. T., \& Slater, M. (1995). Presence and performance within virtual environments. In W. Barfield \& T. A. Furness III (Eds.), Virtual environments and advanced interface design (pp. 474-513). New York: Oxford University Press

Beall. A. C., Loomis, J. M., Philbeck. J. M.. \& Fikes, T. J. (1995). Absolute motion parallax weakly determines visual scale in real and virtual environments. In Proceedings of conference on human vision, visual processing, and digital display (Vol. 2411, pp. 288-297). Bellingham, WA: Society of Photo-Optical Instrumentation Engineers.

BEGAULT, D. R. (1994). 3-D sound for virtual reality and multimedia. New York: AP Professional

Benford, S., Bowers, J.. Fahl.en, L. E., Greenhalgh, C., Mariani, J., \& RODDEN, T. (1995). Networked virtual reality and cooperative work. Presence: Teleoperators \& Virtual Environments, 4, 364-386.
BiocCA, F., \& DeLANEY, B. (1995). Immersive virtual reality technology. In F. Biocca \& M. R. Levy (Eds.), Communication in the age of virtual reality (pp. 57-124). Hillsdale, NJ: Erlbaum.

BloccA, F., \& LEVY, M. R. (1995). Communication in the age of virtual reality. Hillsdale, $\mathrm{NJ}$ : Erlbaum.

Brainard, D. H., Brunt, W. A., \& Speigle, J. M. (1997). Color constancy in the nearly natural image: I. Asymmetric matches. Journal of the Optical Society of America A, 14, 2091-2110.

BurdeA, G., \& COIFFetT, P. (1994). Virtual reality technology. New York: Wiley \& Sons.

CARLILE, S. (1996). Virtual auditory space: Generation and applications. New York: Chapman \& Hall.

Chance, S. S., Gaunet, F., Beall, A. C., \& Loomis, J. M. (1998). Locomotion mode affects the updating of objects encountered during travel: The contribution of vestibular and proprioceptive inputs. Presence: Teleoperators \& Virtual Environments, 7, 168-178.

Cruz-Neira, C., Sandin, T. A., \& DeFantini, R. V. (1993). Surround screen projection-based virtual reality: The design and implementation of the cave. In Proceedings of SIGGRAPH 1993 (pp. 135-142).

DARKEN, R. P.. \& SIBERT, J. L. (1996). Wayfinding strategies and behaviors in large virtual worlds. In Proceedings of the $\mathrm{ACM} C \mathrm{CH} 96$ (pp. 142-149). New York: Association for Computing Machinery.

Durlach, N. I., \& Mavor, A. S. (1995). Virtual reality: Scientific and technological challenges. Washington, DC: National Academy Press.

ELLIS, S. R. (1995). Origins and elements of virtual environments. In W. Barfield \& T. A. Furness III (Eds.), Virtual environments and advanced interface design (pp. 14-57). New York: Oxford University Press.

ElLIS, S. R., \& MENGES, B. M. (1997). Judgments of the distance to nearby virtual objects: Interaction of viewing conditions and accommodative demand. Presence: Teleoperators \& Virtual Environments, 4, 452-460.

ELLIS. S. R.. \& MENGES, B. M. (1999). Operator localization of virtual objects. In Y. Ohta \& H. Tamura (Eds.), Mixed reality: Merging real and virtual worlds (pp. 305-323). Tokyo: Ohmsha.

Feiner, S., Macintyre, B., \& HöLlerer, T. (1999). Wearing it out: First steps toward mobile augmented reality systems. In Y. Ohta \& H. Tamura (Eds.), Mixed reality: Merging real and virtual worlds (pp. 363377). Tokyo: Ohmsha.

FuCHS, H., \& ACKERMAN, J. (1999). Displays for augmented reality: Historical remarks and future prospects. In Y. Ohta \& H. Tamura (Eds.). Mixed reality: Merging real and virfual worlds (pp. 31-40). Tokyo: Ohmsha.

GaLlistel, C. R. (1990). The organization of learning. Cambridge, MA: MIT Press.

GAUNET. F.. \& LoOMIS, J. M. (1999). Self-localization as a function of the informational content of landmarks. Manuscript submitted for publication.

GilkEy, R., \& ANDERSON. T. R. (1997), Binaural and spatial hearing in real and virtual environments. Hillsdale, $\mathrm{NJ}$ : Erlbaum.

Gillner, S., \& MALlot. H. A. (1998). Navigation and acquisition of spatial knowledge in a virtual maze. Journal of Cognitive Neuroscience, $10,445-463$.

Golledge, R. G. (1999). Wayfinding: Cognitive mapping and spatial behavior. Baltimore: Johns Hopkins University Press.

HEETER, C. (1992). Being there: The subjective experience of presence. Presence: Teleoperators \& Virtual Environments, 1, 262-271.

Hei.D, R., \& Durlach, N. I. (1992). Telepresence. Presence: Teleoperators \& Virtual Environments, 1, 109-112.

Hermer. L.. \& SPELKE. E. (1996). Modularity and development: The case of spatial orientation. Cognition, 61, 195-232.

HetTINGER, L. J., \& HAAS, M. W. (in press). Virtual and adaptive environments. Mahwah, $\mathrm{NJ}$ : Erlbaum.

Holmgren. D. E., \& RobinetT, W. (1993). Scanned laser displays for virtual reality: A feasibility study. Presence: Teleoperators \& Virtual Environments, 2, 171-184.

Huttenlocher. J., Newcombe, N., \& Sandberg, E. H. (1994). The coding of spatial location in young children. Cognitive Psychology, 27, 115-147 
IWATA, H. (1999). Feel-through: Augmented reality with force feedback. In Y. Ohta \& H. Tamura (Eds.), Mixed reality: Merging real and virtual worlds (pp. 215-227). Tokyo: Ohmsha.

Jacobs, W. J., Laurance, H. E., \& Thomas, K. G. F. (1997). Place learning in virtual space: I. Acquisition, overshadowing, and transfer. Learning \& Motivation, 28, 521-541.

KALAWSKY, R. S. (1993). The science of virtual reality and virtual environments. Reading, MA: Addison-Wesley.

Klatzky, R. L., Loomis, J. M., Beall, A. C., Chance, S. S., \& GollEDGE, R. G. (1998). Spatial updating of self-position and orientation during real, imagined, and virtual locomotion. Psychological Science, 9, 293-298.

Loomis, J. M. (1992). Distal attribution and presence. Presence: Teleoperators \& Virtual Environments, 1, 113-119.

LOOMIS, J. M., GolledGE, R. G., \& KlatZKY, R. L. (1998). Navigation system for the blind: Auditory display modes and guidance. Presence: Teleoperators \& Virtual Environments, 7, 193-203.

LoOMIS, J. M., KLATZKY, R. L., \& GolledGE, R. L. (1999). Auditory distance perception in real, virtual, and mixed environments. In Y. Ohta \& H. Tamura (Eds.), Mixed reality: Merging real and virtual worlds (pp. 201-214). Tokyo: Ohmsha.

LOOMIS, J. M., \& KNAPP, J. M. (in press). Visual perception of egocentric distance in real and virtual environments. In L. J. Hettinger \& $M$. W. Haas (Eds.), Virtual and adaptive environments. Mahwah, NJ: Erlbaum.

MaY, M., PÉruCh, P., \& Savoyant, A. (1995). Navigating in a virtual environment with map-acquired knowledge: Encoding and alignment effects. Ecological Psychology, 7, 21-36.

McBeath, M. K., Shaffer, D. M., \& Kaiser, M. K. (1995). How baseball outfielders determine where to run to catch fly balls. Science, $\mathbf{2 6 8}$ 569-573.

Meyer, K., APplewhite, H. L., \& BiocCA, F. A. (1992). A survey of position trackers. Presence: Teleoperators \& Virtual Environments, $1,173-200$

Moroney, W. F., \& Moroney, B. W. (1999). Flight simulation. In D. J. Garland, J. A. Wise, \& V. D. Hopkin (Eds.), Handbook of aviation human factors (pp. 355-388). Mahwah, NJ: Erlbaum.

OHTA, Y., \& TAMURA, H. (1999). Mixed reality: Merging real and virtual worlds. Tokyo: Ohmsha.

PALMer, M. T. (1995). Interpersonal communication and virtual reality: Mediating interpersonal relationships. In F. Biocca \& M. R. Levy (Eds.), Communication in the age of virtual reality (pp. 57-124). Hillsdale, NJ: Erlbaum.

Peli, E. (1995, July). Real vision and virtual reality. Optics \& Photonics News, pp. 28-34.

PÉRUCh, P., \& GAUneT, F. (1998). Virtual environments as a promising tool for investigating human spatial cognition. Current Psychology of Cognition, 17, 881-899.

Péruch, P., MaY, M., \& Wartenberg, F. (1997). Homing in virtual environments: Effects of field of view and path layout. Perception, 26, 301-311.

Péruch, P., Vercher, J. L., \& Gauthier, G. M. (1995). Acquisition of spatial knowledge through visual exploration of simulated environments. Ecological Psychology, 7, 1-20.

Pirenne, M. H. (1970). Optics, painting, and photography. Cambridge: Cambridge University Press.

Proffitt, D. R., Bhalla, M., Gossweiler, R., \& Midgett, J. (1995). Perceiving geographical slant. Psychonomic Bulletin \& Review, 2, 409-428.

Regian, J. W., ShebiLSKe, W. L., \& Monk, J. M. (1992). Virtual reality: An instructional medium for visual-spatial tasks. Journal of Communication, 42, 136-149.

Rheingold, H. (1991), Virtual reality. New York: Summit.

Richardson, A. E., Montello, D. R., \& Hegarty, M. (1999). Spatial knowledge acquisition from maps and from navigation in real and virtual environments. Memory \& Cognition, 27, 741-750.
Rolland, J. P., Gibson, W., \& Arierly, D. (1995). Towards quantifying depth and size perception as a function of viewing distance. Presence: Teleoperators \& Virtual Environments, 4, 24-49.

Rossano, M. J., \& MoaK, J. (1998). Spatial representations acquired from computer models: Cognitive load, orientation specificity and the acquisition of survey knowledge. British Journal of Psychology, 89 , $481-497$.

Rothbaum, B. O., Hodges, L. F., \& Kooper, R. (1997). Virtual reality exposure therapy. Journal of Psychotherapy Practice \& Research, 6 , 219-226.

Rothbaum, B. O., Hodges, L. F., Kooper, R., Opdyke, D., WilliFORD, J., \& NORTH, M. M. (1995). Effectiveness of computer-generated (virtual reality) graded exposure in the treatment of acrophobia. American Journal of Psychiatry, 152, 626-628.

Sandstrom, N. J., Kaufman, J., \& HuetTel, S. A. (1998). Males and females use different distal cues in a virtual environment navigation task. Cognitive Brain Research, 6, 351-360.

SHERIDAN, T. (1992). Musings on telepresence and virtual presence. Presence: Teleoperators \& Virtual Environments, 1, 120-126.

Slater, M., Usoh, M., \& STEED, A. (1994). Depth of presence in virtual environments. Presence: Teleoperators \& Virtual Environments, 3, $130-144$.

Stanney, K., \& Salvendy, G. (1998). Aftereffects and sense of presence in virtual environments: Formulation of a research and development agenda. International Journal of Human-Computer Interaction, 10, 135-187.

Steuer, J. (1995). Defining virtual reality: Dimensions determining telepresence. In F. Biocca \& M. R. Levy (Eds.), Communication in the age of virtual reality (pp. 33-56). Hillsdale, NJ: Erlbaum.

STONE, V. E. (1993). Social interaction and social development in virtual environments. Presence: Teleoperators \& Virtual Environments, 2, 153-161.

SURDick, R. T., DAvis, E. T., KING, R. A., \& Honges, L. F. (1997). The perception of distance in simulated visual displays: A comparison of the effectiveness and accuracy of multiple depth cues across viewing distances. Presence: Teleoperators \& Virtual Environments, 6, 513-531.

Sutherland, I. (1965). The ultimate display. Proceedings of the International Federation of Information Processing Congress, 2, 506-508.

Tamura, H., Yamamoto, H., \& Katayama, A. (1999). Steps toward seamless mixed reality. In Y. Ohta \& H. Tamura (Eds.), Mixed reality: Merging real and virtual worlds (pp. 59-79). Tokyo: Ohmsha.

Warren, W. H., \& KaY, B. A. (1997, November). Control law switching during visually guided walking. Paper presented at the 38th Annual Meeting of the Psychonomic Society, Philadelphia.

WENZEL, E. M. (1992). Localization in virtual acoustic displays. Presence: Teleoperators \& Virtual Environments, 1, 80-107.

Wilson, P. N., Foreman, N., Gillett, R., \& Stanton, D. (1997). Active versus passive processing of spatial information in a computersimulated environment. Ecological Psychology, 9, 207-222.

Witmer, B. G., Bailey, J. H., \& KNERr, B. W. (1996). Virtual spaces and real world places: Transfer of route knowledge. International Journal of Human-Computer Studies, 45, 413-428.

WiTMER, B. G., \& KLINE, P. B. (1998). Judging perceived and traversed distance in virtual environments. Presence: Teleoperators \& Virtual Environments, 7, 144-167.

WITMER, B. G., \& SADOWSKI, W. J., JR. (1998). Non-visually guided locomotion to a previously viewed target in real and virtual environments. Human Factors, 40, 478-488.

Yang, T. L., Dixon, M. W., \& Proffitt, D. R. (1999). Seeing big things: Overestimation of heights is greater for real objects than for objects in pictures. Perception, 28, 445-467.

(Manuscript received July 20, 1998; revision accepted for publication April 2, 1999.) 